\title{
Pengelolaan dan Analisis Nilai Tambah By-Products Industri Gula (Studi Kasus di Pabrik Gula Gempolkrep, Mojokerto, Jawa Timur)
}

\section{(Management and Value-Added Analysis of Sugar Industry By-Products Utilization (Case Study in Gempolkrep Sugar Factory, Mojokerto, East Java))}

\author{
Relita Novianti ${ }^{1 *}$, Yusman Syaukat ${ }^{2}$, Meti Ekayani ${ }^{2}$ \\ (Diterima Agustus 2020/Disetujui Mei 2021)
}

\begin{abstract}
ABSTRAK
Industri gula merupakan salah satu industri berbasis pertanian dengan menjadikan tebu sebagai bahan baku untuk menghasilkan gula. Proses pengolahan tebu menjadi gula menghasilkan produk sampingan (by-products) berupa ampas tebu, tetes tebu, dan blotong yang apabila tidak diolah akan menimbulkan pencemaran lingkungan. Pada penelitian ini dilakukan identifikasi pola pemanfaatan by-products industri gula di PG Gempolkrep dan analisis nilai tambah dari hasil pengolahan by-products industri gula menggunakan Metode Hayami. Berdasarkan pola pemanfaatan di PG Gempolkrep, ampas tebu dimanfaatkan menjadi bahan bakar untuk menghasilkan listrik guna mencukupi kebutuhan listrik selama proses produksi gula. Tetes tebu digunakan sebagai bahan baku untuk memproduksi bioetanol. Blotong dimanfaatkan menjadi bahan baku pembuatan pupuk kompos. Nilai tambah yang diperoleh dari pengolahan blotong menjadi pupuk kompos sebesar Rp141.335 per ton, sedangkan untuk produk bioetanol dari tetes tebu memberikan nilai tambah sebesar Rp752.645 per ton.
\end{abstract}

Kata kunci: ampas tebu, bioetanol, blotong, metode Hayami, nilai tambah, tetes tebu

\section{ABSTRACT}

The sugar industry is one of the agriculture-based industries which use sugar cane as a raw material to produce sugar. The processing of sugar cane into sugar generates by-products such as bagasse, molasses, and filter cake which will cause environmental pollution if they are untreated. This research identified the utilization pattern of sugar industry by-products in Gempolkrep Sugar Factory and analyzed the added value from by-products utilization using Hayami Method. Based on the utilization pattern at Gempolkrep Sugar Factory, bagasse is used as an alternative raw material for electricity generation. Filter cake is used as raw material for compost fertilizer. Molasses is used as a raw material for bioethanol manufacture. The added value obtained from processing filter cake into compost is IDR141.335 per ton, while bioethanol products from molasses provide an added value of IDR752.645 per ton.

Keywords: bagasse, bioethanol, filter cake, Hayami method, molasses, value added

\section{PENDAHULUAN}

Tebu merupakan salah satu komoditas unggulan Indonesia karena tebu merupakan bahan baku pembuat gula, di mana gula merupakan salah satu bahan pokok penting (Tarimo \& Takamura 1998). Menurut Pipo \& Luengo (2013), komoditas tebu sendiri dipandang sebagai agroindustri yang dianggap dapat memberikan kesempatan besar bagi pembangunan ekonomi di beberapa negara penghasil tebu. Industri gula yang menggunakan bahan baku tebu juga dianggap sebagai sumber pendapatan bagi para

1 Pusat Penelitian Limnologi Lembaga IImu Pengetahuan Indonesia (LIPI), Jl. Raya Bogor Jkt, Cibinong, Bogor, Jawa Barat 16911

2 Departemen Ekonomi Sumberdaya dan Lingkungan, Fakultas Ekonomi dan Manajemen, Institut Pertanian Bogor, Kampus IPB Darmaga, Bogor 16620

* Penulis Korespondensi: Email: relita@limnologi.lipi.go.id petani tebu, pengusaha, maupun pekerja di bidang industri gula.

Permintaan gula pasir Indonesia relatif tinggi seiring dengan pertambahan jumlah penduduk, perkembangan industri makanan dan minuman, serta perkembangan hotel dan restoran. Tercatat bahwa konsumsi gula di Indonesia pada tahun 2018 adalah sebesar 7.181 juta ton ${ }^{3}$ dan sebanyak $80 \%$ dari kebutuhan gula tersebut dipenuhi dengan gula impor (BPS 2019). Sampai dengan saat ini pemerintah terus berupaya meningkatkan produksi gula guna memenuhi kebutuhan konsumsi gula dan mengurangi impor dengan menyusun Rencana Strategis Badan Penelitian dan Pengembangan Pertanian 2015-2019, dengan isu dan sasaran strategis litbang perkebunan adalah 1) pencapaian swasembada gula, 2) nilai tambah, daya saing, dan mengcounter kampanye hitam/negatif yang berkaitan dengan lingkungan dan kesehatan yang keduanya akan dicapai melalui fokus litbang pada upaya peningkatan produktivitas tebu. 
Selain itu, terkait dengan isu lingkungan, pada saat ini litbang perkebunan juga berupaya mengembangkan berbagai komoditas dan teknologi bioenergi (Kementan 2016).

Selain berupaya untuk meningkatkan produksi gula, hal lain yang perlu diperhatikan adalah produk sampingan industri gula. Pada proses pengolahan tebu, pabrik gula tidak hanya menghasilkan gula sebagai produk utama, namun juga menghasilkan produk sampingan (by-products) yang dapat berbentuk padat dan cair (Deptan 2007). By-products tersebut apabila tidak dimanfaatkan akan menjadi limbah yang menyebabkan pencemaran lingkungan. Menurut Moertinah (2010), industri gula sendiri merupakan industri dengan karakteristik air limbah yang memiliki nilai $B O D$ dan $C O D$ yang tinggi sehingga limbah industri gula jika dibiarkan dan tidak dikelola akan menimbulkan gangguan pada kesehatan manusia dan pencemaran lingkungan. Limbah pabrik gula juga memiliki warna dan bau yang menyengat ketika dilepaskan ke lingkungan tanpa perawatan yang tepat, sehingga hal ini cukup mengganggu kehidupan manusia dan makhluk hidup lainnya (Saranraj \& Stella 2014).

Menurut Halim (2007), produk sampingan (byproducts) merupakan produk yang dihasilkan dalam proses produksi, namun produk tersebut relatif harganya/ nilainya/ kuantitasnya lebih rendah dibanding yang lain. Berdasarkan kondisinya, byproducts dapat diklasifikasikan menjadi dua kelompok, yakni by-products yang dapat dipasarkan tanpa adanya proses terlebih dahulu dan by-products yang membutuhkan proses pengolahan lanjutan lebih dulu agar dapat dipasarkan (Carter \& Milton 2009).

Di balik berbagai upaya yang dilakukan untuk swasembada gula terdapat hal lain yang perlu mendapatkan perhatian, yaitu berupa by-products industri gula yang dapat menimbulkan kerugian. Gangguan yang disebabkan oleh by-products industri gula berupa gangguan kesehatan dan kerusakan lingkungan. Menurut WWF (2016), produk sampingan (by-products) industri gula yang dilepaskan ke lingkungan tanpa dilakukan pengolahan akan mengakibatkan gangguan pada fungsi ekologi, terutama pencemaran daerah perairan sehingga dapat membahayakan organisme perairan dan mengancam ketersedian air bagi manusia. Oleh karena itu, upayaupaya pengolahan dan pemanfaatan by-products industri gula diperlukan untuk mengurangi dampak lingkungan yang disebabkan oleh by-products tersebut.

Penelitian ini bertujuan untuk mengetahui pola pemanfaatan produk sampingan (by-products) industri gula dan nilai tambah yang diperoleh dari pengolahannya.

\section{METODE PENELITIAN}

Penelitian ini dilakukan di Pabrik Gula Gempolkrep dan PT. Enero yang berada di Desa Gempolkrep, Kecamatan Gedek, Kabupaten Mojokerto, Jawa Timur pada bulan Mei-Juni 2016. Penentuan lokasi dilakukan secara purposive karena PG Gempolkrep merupakan salah satu pabrik gula yang memiliki kapasitas giling yang cukup besar setiap musim panen tebu. Selain memproduksi gula, PG Gempolkrep juga telah memanfaatkan produk sampingan gula, yaitu blotong menjadi pupuk kompos. Di lokasi yang berdekatan terdapat PT. Enero yang merupakan pabrik yang memproduksi bioethanol dengan melakukan pemanfaatan produk sampingan gula yang berupa tetes tebu.

Data yang digunakan merupakan data primer dan data sekunder. Data primer diperoleh melalui penelitian langsung pada pabrik gula beserta wawancara langsung dengan para informan kunci (key informant). Data sekunder diperoleh dari arsip data milik pabrik gula dan pabrik serta data dari lembagalembaga terkait, seperti BPS. Data yang diperoleh dari pabrik gula adalah mengenai berapa jumlah produksi gula dalam satu masa giling dan berapa jumlah produk sampingan yang dihasilkan dalam masa giling tersebut.

Analisis pola pemanfaatan by-producst industri gula Pabrik Gula Gempolkrep dilakukan secara deskriptif kualtitatif yang ditunjukkan pada Gambar 1 dan 2. Sementara itu, analisis nilai tambah dari pengolahan by-products gula menggunakan Metode Hayami yang ditunjukkan pada Tabel 1, 2, dan 3.

Nilai tambah dipengaruhi oleh faktor teknis dan nonteknis (faktor pasar). Faktor teknis terdiri atas jumlah dan kualitas bahan baku serta input penyerta, kualitas produk, penerapan teknologi, kapasitas produksi, dan penggunaan unsur tenaga kerja. Sementara itu, faktor pasar meliputi harga bahan baku, harga jual output, upah tenaga kerja, modal investasi, informasi pasar, dan nilai input lain (selain bahan bakar). Dengan demikian, fungsi nilai tambah yang menggambarkan imbalan bagi tenaga kerja, modal, dan manajemen dapat dirumuskan pada Tabel 1 (Hayami et al. 1987).

\section{HASIL DAN PEMBAHASAN}

\section{Pola Pemanfaatan By-Products Industri Gula}

Pada dasarnya, pemanfaatan utama tebu di Indonesia adalah untuk menghasilkan gula, begitu juga yang dilakukan oleh PG Gempolkrep. Dalam proses pengolahan tebu menjadi gula dihasilkan beberapa byproducts yang sebenarnya dapat diolah dan dimanfaatkan lebih lanjut. Jenis by-products yang 
Tabel 1 Analisis perhitungan nilai tambah Hayami

\begin{tabular}{|c|c|}
\hline Variabel & Nilai \\
\hline \multicolumn{2}{|l|}{ Output, Input, harga } \\
\hline Output/ total produksi (Unit/periode) & A \\
\hline Input bahan baku (Unit/Periode) & $\mathrm{B}$ \\
\hline Input tenaga kerja (HOK/periode) & C \\
\hline Faktor konversi (1) / (2) & $D=A / B$ \\
\hline Koefisien tenaga kerja (3) / (2) & $E=C / B$ \\
\hline Harga produk (Rp / unit) & $\mathrm{F}$ \\
\hline Upah rata-rata tenaga kerja per $\mathrm{HOK}(\mathrm{Rp} / \mathrm{HOK})$ & G \\
\hline \multicolumn{2}{|l|}{ Pendapatan dan Keuntungan } \\
\hline Harga input bahan baku (Rp / unit) & $\mathrm{H}$ \\
\hline Sumbangan input lain (Rp) & I \\
\hline Nilai produk (4) x (6) (Rp / produk) & $\mathrm{J}=\mathrm{DxF}$ \\
\hline a. Nilai tambah (10)-(8)-(9) (Rp/produk) & $\mathrm{K}=\mathrm{J}-\mathrm{H}-\mathrm{i}$ \\
\hline b. Rasio nilai tambah (11a) / (10) (\%) & $\mathrm{L} \%=(\mathrm{K} / \mathrm{J}) \%$ \\
\hline a. Pendapatan Tenaga Kerja (Rp / produk) & $\mathrm{M}=\mathrm{E} \times \mathrm{G}$ \\
\hline b. Imbalan Tenaga Kerja (12a)/(11a) (\%) & $\mathrm{N} \%(\mathrm{M} / \mathrm{K}) \%$ \\
\hline a. Keuntungan (11a)-(12a) (Rp/produk) & $\mathrm{O}=\mathrm{K}-\mathrm{M}$ \\
\hline b. Tingkat Keuntungan (13a)/(10)(\%) & $\mathrm{P} \%=(\mathrm{O}-\mathrm{J}) \%$ \\
\hline \multicolumn{2}{|l|}{ Balas Jasa untuk Faktor Produksi } \\
\hline Marjin (10)-(8) (Rp/produk) & $\mathrm{Q}=\mathrm{J}-\mathrm{H}$ \\
\hline a. Pendapatan tenaga kerja (12a)/(14) (\%) & $R \%=(M / Q) \%$ \\
\hline b. Sumbangan input lain (9) / (14) (\%) & $S \%=(I / Q) \%$ \\
\hline c. Keuntungan perusahaan (13a /(14) (\%) & $\mathrm{T} \%=(\mathrm{O} / \mathrm{Q}) \%$ \\
\hline
\end{tabular}

Sumber: Hayami et al. 1987.

Tabel 2 Perhitungan nilai tambah blotong menjadi pupuk kompos

\begin{tabular}{llr}
\hline \multicolumn{1}{c}{ Variabel } & Satuan & Pupuk kompos \\
\hline Output, Input, harga & & 18.740 \\
Output/ total pupuk kompos & Ton/tahun & 18.740 \\
Input bahan baku blotong & Ton/tahun & 2.500 \\
Input tenaga kerja & HOK/tahun & 1 \\
Faktor konversi & - & 0,13 \\
Koefisien tenaga kerja & - & 250.000 \\
Harga produk & Rp/ton & \\
Upah rata-rata tenaga kerja & Rp/HOK & 62.000 \\
& & 80.000 \\
Pendapatan dan keuntungan & Rp/ton & 28.465 \\
Harga input bahan baku & Rp/ton & 250.000 \\
Sumbangan input lain (Rp) & Rp/ton & 141.535 \\
Nilai produk & Rp/ton & 56,61 \\
a. Nilai tambah & $\%$ & 8.271 \\
b. Rasio nilai tambah & Rp/ton & 5,84 \\
a. Share Tenaga Kerja & $\%$ & 133.264 \\
b. Share Tenaga Kerja & Rp/ton \\
a. Keuntungan & $\%$ & 53,31 \\
b. Tingkat Keuntungan & & 170.000 \\
Balas jasa faktor produksi & $\%, 87$ \\
Marjin & Rp/ton & 16,74 \\
a. Pendapatan tenaga kerja & $\%$ & 78,39 \\
b. Sumbangan input lain & $\%$ & \\
c. Keuntungan perusahaan & $\%$ & \\
\hline
\end{tabular}

dihasilkan antara lain adalah ampas tebu yang dihasilkan pada proses ekstraksi, kemudian blotong yang dihasilkan pada proses pemurnian, selanjutnya dihasilkan tetes tebu pada proses kristalisasi. Alur proses pembuatan gula dan produk sampingan yang dihasilkan dapat dilihat pada Gambar 1.

Inovasi yang berkembang beberapa tahun terakhir menujukkan adanya suatu upaya pemanfaatan produk samping yang dihasilkan bersamaan dengan produksi gula (Pipo \& Luengo 2013). Pabrik gula pada saat ini mulai melakukan beberapa inovasi dalam pemanfaatan limbah sehingga hasil sampingan gula (by-products) dapat diolah dan memiliki nilai jual. Oleh karena itu, by-products industri gula dapat dikatakan sebagai suatu sumber daya. Di mana, sumber daya yang dikelola secara baik akan memberikan manfaat 
Tabel 3 Perhitungan nilai tambah tetes tebu menjadi bioetanol

\begin{tabular}{|c|c|c|}
\hline Variabel & Satuan & Nilai \\
\hline \multicolumn{3}{|l|}{ Output, Input, harga } \\
\hline Output/ total bioetanol & Ton/tahun & 4.934 \\
\hline Input bahan baku tetes & Ton/tahun & 24.310 \\
\hline Input tenaga kerja & HOK/tahun & 29.760 \\
\hline Faktor konversi & - & 0,20 \\
\hline Koefisien tenaga kerja & - & 1,22 \\
\hline Harga produk & Rp/ton & 10.827 .039 \\
\hline Upah rata-rata tenaga kerja & $\mathrm{Rp} / \mathrm{HOK}$ & \\
\hline \multirow{2}{*}{\multicolumn{3}{|c|}{ Pendapatan dan Keuntungan }} \\
\hline & & \\
\hline Sumangan & Rp/ton & 1.028 .000 \\
\hline Sumbangan input lain & Rp/ton & 416.830 \\
\hline Nilai produk & Rp/ton & 2.197 .475 \\
\hline a. Nilai tambah & Rp/ton & 752.645 \\
\hline b. Rasio nilai tambah & $\%$ & 34,25 \\
\hline a. Pendapatan Tenaga Kerja & $\mathrm{Rp} / \mathrm{ton}$ & 187.301 \\
\hline b. Imbalan Tenaga Kerja & $\%$ & 24,89 \\
\hline a. Keuntungan & $\mathrm{Rp} /$ ton & 565.344 \\
\hline \multirow[t]{2}{*}{ b. Tingkat Keuntungan } & $\%$ & \\
\hline & & 25,73 \\
\hline \multicolumn{3}{|l|}{ Balas Jasa untuk Faktor Produksi } \\
\hline Marjin & Rp/ton & 1.169 .475 \\
\hline a. Pendapatan tenaga kerja & $\%$ & 16,02 \\
\hline b. Sumbangan input lain & $\%$ & 35,64 \\
\hline c. Keuntungan perusahaan & $\%$ & 48,34 \\
\hline
\end{tabular}

yang sebesar-besarnya bagi umat manusia (Fauzi 2004).

Ampas tebu yang merupakan residu padat tebu setelah proses ekstraksi dapat dimanfaatkan menjadi bahan bakar boiler karena ampas tebu merupakan sumber energi terbarukan dan tersedia cukup besar (Hugot 1986). Pabrik Gula Gempolkrep sendiri telah memanfaatkan ampas tebu sebagai bahan bakar boiler dan hal tersebut cukup menghemat penggunaan energi listrik. Ampas tebu digunakan sebagai bahan bakar boiler untuk menghasilkan uap. Uap yang dihasilkan oleh boiler digunakan untuk menggerakkan generator turbin hingga menghasilkan energi listrik. Energi listrik yang dihasilkan oleh turbin alternator digunakan kembali oleh pabrik gula untuk memasok energi listrik yang diperlukan selama proses produksi gula. Maka dari itu, ampas tebu cukup bermanfaat karena dapat menjadi energi alternatif untuk mencukupi kebutuhan bahan bakar pabrik gula. Dengan menggunakan energi ampas tebu secara efisien, nantinya pabrik gula akan dapat mencukupi kebutuhan energi secara mandiri.

Tetes tebu digunakan sebagai bahan baku pembuatan bioetanol melalui pabrik bioetanol. Dibandingkan bahan baku lain, tetes mempunyai keunggulan, yaitu selain harganya murah juga mengandung 50\% gula sederhana yang dapat difermentasi langsung oleh yeast menjadi etanol tanpa pretreatment (Wardani dan Fenty 2013). Bioetanol sendiri merupakan salah satu sumber energi alternatif pengganti BBM yang terbuat dari proses fermentasi bahan-bahan alami oleh mikroorganisme (Jeon 2007). Tetes tebu yang dihasilkan pada saat produksi gula disalurkan kepada pabrik bioetanol, yaitu PT. Enero untuk diolah menjadi bioetanol. Pada tahun 2014, hasil produksi bioetanol telah diekspor ke negara Filipina.Tidak hanya diekspor, hasil pengolahan tetes tebu dari PT. Enero juga dikonsumsi oleh industriindustri dalam negeri.

Blotong atau yang biasa disebut dengan filter cake, dihasilkan pada saat proses pemurnian gula. Blotong biasanya dimanfaatkan oleh pabrik pupuk untuk diolah menjadi pupuk kompos karena blotong merupakan limbah pabrik gula yang berbentuk padat, berwarna hitam seperti lumpur, dan masih mengandung bahan organik serta mineral (Purwaningsih 2011). Menurut Nahdodin et al. (2008), rata-rata standar produksi blotong pada masing-masing pabrik gula umumnya sebesar 2,5\% dari jumlah keseluruhan tebu yang digiling. Pada umumnya blotong ini diakumulasi di lapangan terbuka di sekitar pabrik gula, sebelum dimanfaatkan untuk pertanian (Lahuddin 1996). Pabrik Gula Gempolkrep sendiri telah mengolah blotong tersebut menjadi pupuk kompos. Pupuk kompos yang dihasilkan sangat bermafaat dalam proses budi daya karena dapat diaplikasikan di lahan kering guna meningkatkan pertumbuhan dan hasil tebu itu sendiri. Pupuk kompos tersebut kemudian disalurkan kepada petani-petani tebu dan diaplikasikan pada lahan tebu. Alur pola pemanfaatan by-products gula disajikan pada Gambar 2.

\section{Nilai Tambah Pemanfaatan By-Products \\ - Nilai tambah blotong menjadi pupuk kompos}

Menurut Sudiyono (2004), menghitung nilai tambah dengan cara menggabungkan metode nilai tambah untuk pengolahan dan nilai tambah untuk pemasaran. Dengan Metode Hayami, dapat diketahui faktor konversi, koefisien tenaga kerja, nilai produk, nilai tambah, rasio nilai tambah, imbalan tenaga kerja, 
sumbangan input lain, tingkat keuntungan, dan marginnya.

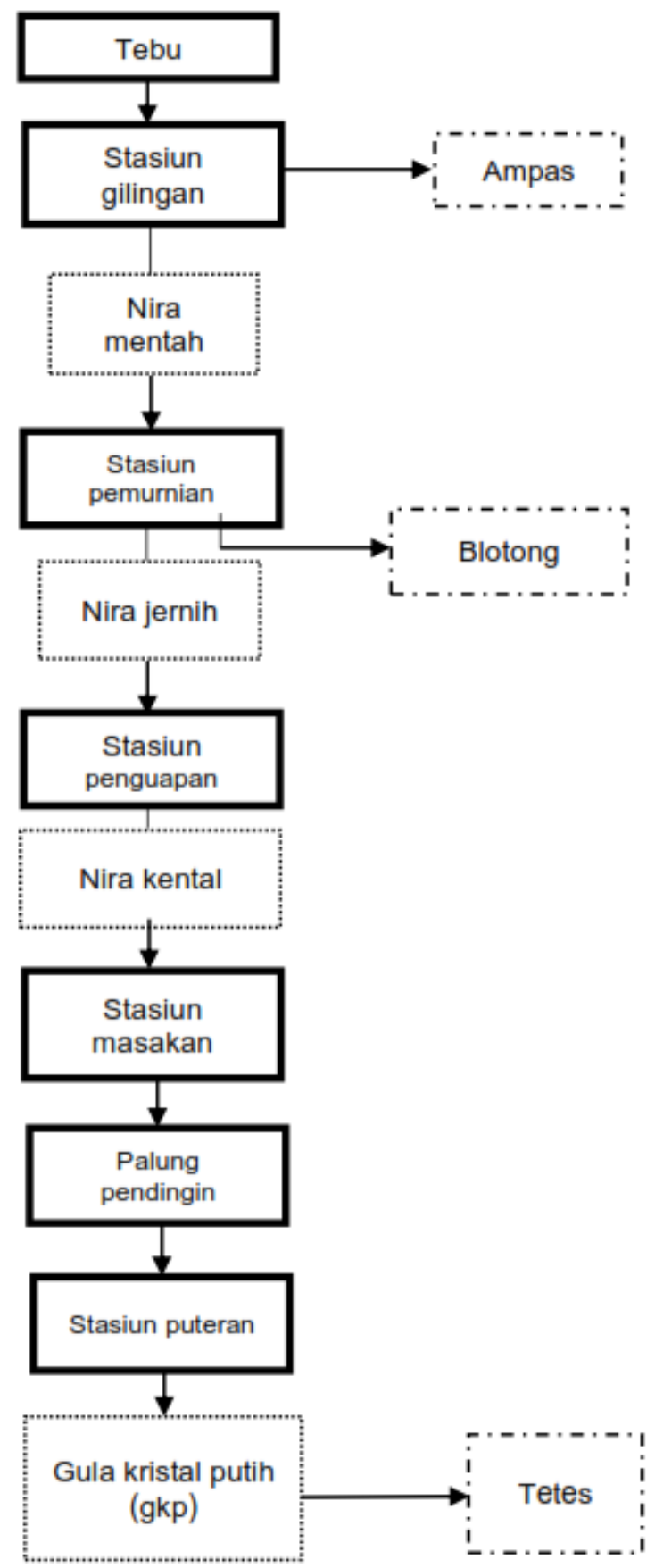

Gambar 1 Alur proses produksi gula. $\square=$ Stasiun proses, = Materi yang dihasilkan, dan $=$ by-products.

Sumber: Pabrik Gula Gempolkrep (2016).

Berdasarkan hasil analisis Tabel 2 dapat dijelaskan bahwa nilai tambah pada setiap pengolahan produk sampingan (by-products) industri gula memberikan nilai yang berbeda. Nilai tambah yang diperoleh dari hasil pengolahan blotong menjadi pupuk kompos adalah Rp141.535/ton.

\section{- Nilai tambah tetes tebu}

Berdasarkan perhitungan menggunakan Metode Hayami, nilai tambah yang diperoleh dari hasil pengolahan tetes tebu menjadi sebesar Rp752.645/ton. Keuntungan tertinggi diperoleh dari hasil pemanfaatan tetes tebu menjadi bioetanol sebesar Rp565.344/ton. Estimasi nilai tambah bioetanol secara lebih rinci dapat dilihan pada Tabel 3.

\section{KESIMPULAN}

Proses produksi gula di PG Gempolkrep menghasilkan by-products, yaitu ampas tebu (bagasse), tetes tebu (molases), dan blotong (filter mud). Berdasarkan pola pemanfaatan di PG Gempolkrep, ampas tebu dimanfaatkan menjadi bahan bakar untuk menghasilkan listrik guna mencukupi kebutuhan listrik selama proses produksi gula. Tetes tebu digunakan sebagai bahan baku untuk memproduksi bioetanol melalui PT Enero. Blotong dimanfaatkan menjadi bahan baku pembuatan pupuk kompos. Nilai tambah yang diperoleh dari pengolahan blotong menjadi pupuk kompos sebesar Rp141.335/ton, sedangkan untuk produk bioetanol memberikan nilai tambah sebesar Rp752.645/ton. Proporsi balas jasa terbesar untuk kedua produk tersebut terdapat pada perusahaan.

\section{DAFTAR PUSTAKA}

[BPS] Badan Pusat Statistik. 2019. Distribusi Perdagangan Komoditas Gula Pasir: Badan Pusat Statistik Republik Indonesia. ISBN : 978-602-438312-1. Jakarta (ID).

[Deptan] Departemen Pertanian. 2007. Pedoman teknis pemanfaatan limbah perkebunan menjadi pupuk organik. [Intenet]. [diunduh 2016 Jan 1]. Tersedia pada: http://psp.pertanian.go.id/ assets/file/2015/Pedoman\%20Teknis\%20UPPO\% 202015.pdf

Carter W, Milton F, Ursy. 2009. Akuntansi Biaya. Edisi Keempat Belas. Terjemahan. Jakarta (ID): Salemba Empat.

Fauzi A. 2004. Ekonomi Sumber daya Alam dan Lingkungan: Teori dan Aplikasi. Jakarta (ID) : Gramedia Pustaka Utama.

Halim A. 2007. Dasar-Dasar Akuntansi Biaya. Yogyakarta (ID): BPFE.

Hayami Y, Toshihiko K, Yoshinori M, dan Masdjidin S. 1987. Agricultural Marketing and Processing in Upland Java A Perspective of Sunda Village. Bogor (ID): CGPRT Centre 


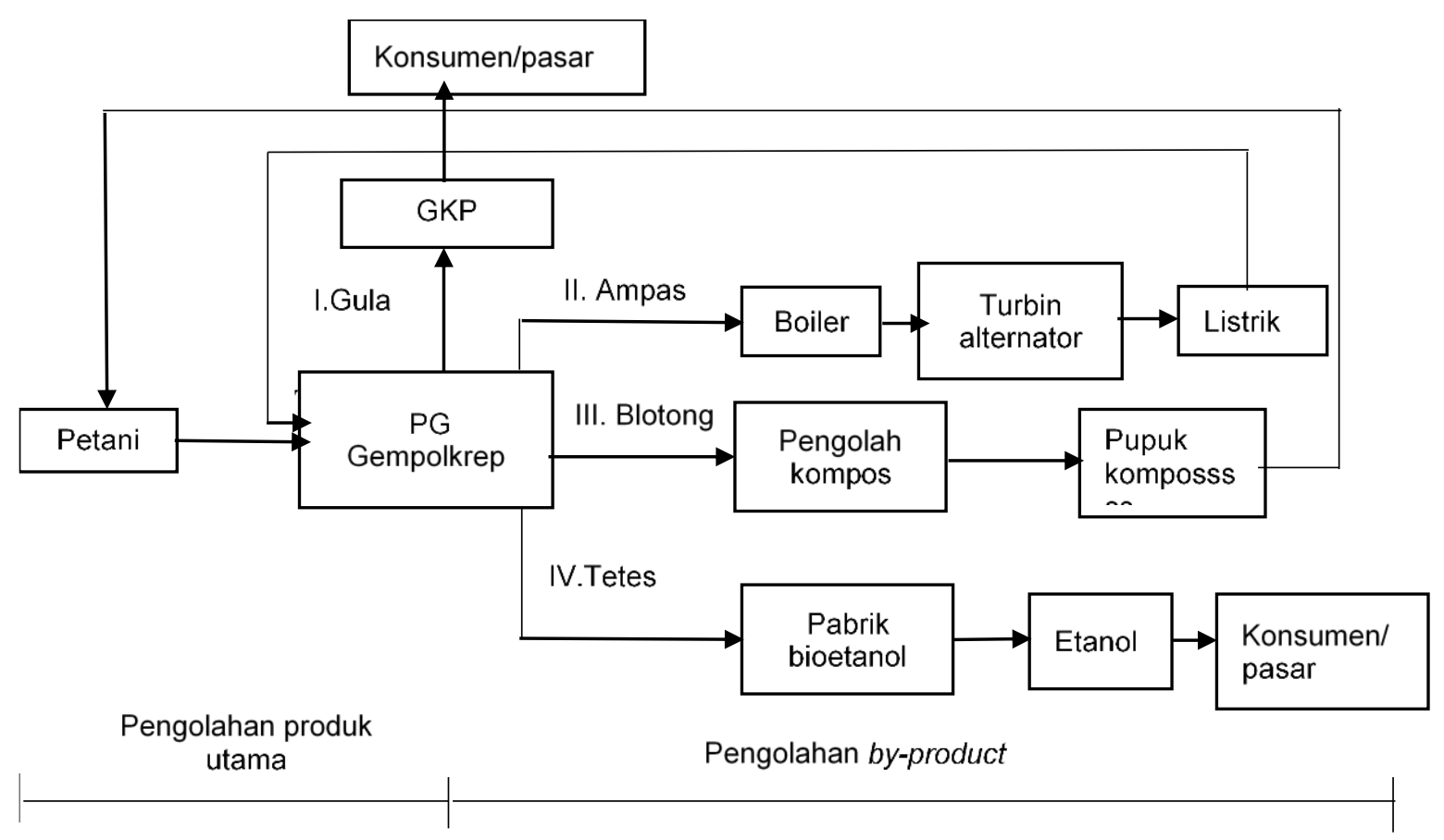

Gambar 2 Pola Pemanfaatan by-products Gula pada Pabrik Gula Gempolkrep.

Hugot E. 1986. Handbook of Cane Sugar Engineering, (3rd ed). NewYork (US): Elsevier Science Publishing Company Inc.

Jeon B.Y. (2007). Development of a serial bioreactor system for direct ethanol production from starch using Aspergillus niger and Saccharomyces cerevisiae. Biotechnology and Bioprocess Engineering 12: 566-573. https://doi.org/ 10.1007/BF02931356

[Kementan] Kementerian Pertanian. 2016. Keputusan Kepala Badan Penelitian dan Pengembangan Pertanian. Nomor 156.1 / Kpts/RC 020/ I/ 04/ 2016. Jakarta (ID).

Lahuddin. 1996. Pengaruh kompos blotong terhadap beberapa sifat fisik dan kandungan unsur hara tanah serta hasil tanaman jagung. Jurnal Penelitian Pertanian. 1: 13-18.

Moertinah S. 2010. Kajian proses aerobik sebagai alternatif teknologi pengelolaan air limbah indutri organik tinggi. Jurnal Riset Teknologi Pencegahan Pencemaran Industri. 1(2): 104-114.

Nahdodin SH, Ismail I, Rusmanto J. 2008. Kiat mengatasi kelangkaan pupuk untuk mempertahankan produktivitas tebu dan produksi gula nasional. [Internet]. [diunduh 2016 Januari 18]. Tersedia pada: https://www.yumpu.com/ id/document/view/15883936/kiat-mengatasikelangkaan-pupuk-untuk-p3gi .
Pippo, Luengo. 2013. Sugarcane energy use: Accounting of feedstock energy considering current agro-industrial trends and their feasibility. International Journal of Energy andEnvironmental Engineering 2013: 4-10. https://doi.org/10.1186/ 2251-6832-4-10

Purwaningsih E. 2011. Pengaruh pemberian kompos blotong, legin, dan mikoriza terhadap serapan hara $\mathrm{N}$ dan $\mathrm{P}$ tanaman kacang tanah. Widya Warta No 02 Tahun XXXV. Jakarta (ID).

Saranraj PD, Stella. 2014. Impact of sugar mill effluent to environment and bioremediation: A review. World Applied Sciences Journal. 30(3): 299-316.

Sudiyono A. 2004.Pemasaran Pertanian. Malang (ID) : Universitas Muhammadiyah Malang.

Tarimo A, Takamura Y. 1998. Sugarcane Production, Processing and Marketing in Tanzania. African Study Monographs 19(1): 1-11.

Wardani A, Fenty N. 2013. Produksi etanol dari tetes tebu oleh Saccharomyces cerevisiae pembentuk flok (NRRL-Y 265). Agritech. 33(2): 131-139.

[WWF] World Wildlife Fund. 2016. Sustainable Agriculture : Sugarcane. [Internet]. Diakses pada: 2016 April 11. Tersedia pada: http://www. worldwildlife.org/industries/sugarcane. 